\title{
КЛИМАТИЧЕСКАЯ НЕОДНОРОДНОСТЬ ТЕМПЕРАТУРЫ ВОЗДУХА НА ТЕРРИТОРИИ ВОСТОЧНОЙ ЕВРОПЫ В ВЕСЕННИЙ ПЕРИОД
}

\author{
Л. М. Акимов, Т. Н. Задорожная, В. П. Закусилов
}

\author{
Воронежский государственный университет, Россия \\ Военный учебно-научный цеентр ВВС «Военно-воздушная академия им. проф. Н. Е. Жуковского и \\ Ю. А. Гагарина», Россия \\ Поступила в редакциюю 6 июля 2018 г.
}

\begin{abstract}
Аннотация: В статье детально рассмотрен климатический режим средней месячной температуры воздуха в весенний период (на примере апреля месяца) на различных $2,5^{\circ}$ участках Восточной Европы. Показана его изменчивость и границы, в которых находятся их экстремальные значения. Подтвержден вывод о наблюдающемся потеплении по данным как средних, так и экстремальных значений температуры, с тенденцией в широтном и меридиональном направлениях. Полученные результаты могут быть использованы в качестве практических рекомендаций при перспективном зонировании с учетом биоклиматического потенциала.
\end{abstract}

Ключевые слова: средняя месячная температура воздуха, апрель, Восточная Европа, климатические параметры, нормы, изменение, тенденция.

Abstract: The climate regime of the average monthly air temperature in the spring period (in the example of April) in various $2.5^{\circ}$ of Eastern Europe was studied in detail. It shows its variability and the boundaries in which their extreme values are found. The conclusion about the observed warming is confirmed according to the data of both average and extreme temperature values. The trends of this warming in the latitudinal and meridional directions are shown. The obtained results can be used as practical recommendations for the prospective zoning of the territory according to the bioclimatic potential of the territory.

Key words: average monthly air temperature, April, Eastern Europe, climatic parameters, norms, change, trend.

В 2016 году Всемирная метеорологическая организация (BMO) опубликовала ежегодный доклад о глобальном климате, в котором содержится предупреждение о катастрофических климатических изменениях [5]. По данным Росгидромета на территории России в последние десятилетия потепление климата происходило быстрее и масштабнее, чем на остальной части Земного шара. C климатическими изменениями связаны опасные гидрометеорологические явления, такие как паводки, наводнения, сильный ветер, ливневые дожди, град, засухи, на которые приходится до $90 \%$ самых тяжелых экономических потерь. Росгидромет отмечает, что за период 1990-2000 годов на территории России ежегодно фиксировалось 150200 опасных гидрометеорологических явлений (ОЯ), нанесших значительный ущерб. В последующие годы их число выросло до 250-300 в год, а

( Акимов Л. М., Задорожная Т.Н., Закусилов В.П., 2019 начиная с 2007 года, в среднем, один раз в два года число таких ОЯ превысило 400. Опасные явления, наблюдаемые в течение двух последних десятилетий, оказались наиболее интенсивными и разрушительными.

Показателем климатических изменений, и даже ответственным за происходящие явления, выступает аномальное проявление температуры воздуха, которая с начала XX столетия выросла на $0,74^{\circ} \mathrm{C}$. Примерно две трети этого повышения температуры приходится на период после 1980 года $[6,7,8]$. С этим связана необходимость углубленного изучения температурного режима в отдельных регионах и выявления их временной тенденции.

Многочисленные исследования [1, 2, 3, 4, 9, 10] показывают, что скорость изменения климата неоднородна, как в пространстве, так и во времени. Такая ситуация вынуждает специалистов проводить постоянное слежение за скоростью измене- 
Распределение норм среднемесячной температуры воздуха $\bar{T}_{i, j}$ за период 1958-1979 годов в узлах географической сетки $i, j$ с шагом $2,5^{\circ}$, широтная зона 40-60

\begin{tabular}{|l|c|c|c|c|c|c|c|c|c|c|c|c|c|}
\hline \multicolumn{10}{|c|}{ Восточная долгота, град } \\
\hline $\begin{array}{l}\text { с.ш. } \\
\text { град }\end{array}$ & 30 & 32,5 & 35 & 37,5 & 40 & 42,5 & 45 & 47,5 & 50 & 52,5 & 55 & 57,5 & 60 \\
\hline 60 & 2,4 & 2,8 & 2,2 & 2,1 & 2,0 & 1,9 & 1,7 & 1,5 & 1,4 & 1,2 & 1,0 & 0,9 & 0,6 \\
\hline 57,5 & 3,8 & 3,8 & 3,8 & 3,8 & 3,8 & 3,7 & 3,6 & 3,4 & 3,2 & 3,0 & 2,8 & 2,7 & 2,5 \\
\hline 55 & 5,2 & 5,2 & 5,2 & 5,2 & 5,3 & 5,2 & 5,1 & 5,0 & 4,8 & 4,6 & 4,5 & 4,5 & 4,4 \\
\hline 52,5 & 7,3 & 7,2 & 7,1 & 7,1 & 7,0 & 6,9 & 6,8 & 6,6 & 6,5 & 6,4 & 6,3 & 6,2 & 6,1 \\
\hline 50 & 9,0 & 8,8 & 8,7 & 8,6 & 8,5 & 8,4 & 8,3 & 8,2 & 8,1 & 8,0 & 7,9 & 7,6 & 7,3 \\
\hline 47,5 & 9,3 & 9,1 & 9,0 & 9,2 & 9,4 & 9,4 & 9,5 & 9,5 & 9,6 & 9,6 & 9,6 & 9,4 & 9,1 \\
\hline 45 & 9,4 & 9,2 & 9,6 & $\mathbf{1 0 , 1}$ & $\mathbf{1 0 , 6}$ & $\mathbf{1 0 , 8}$ & $\mathbf{1 0 , 9}$ & $\mathbf{1 1 , 0}$ & $\mathbf{1 1 , 2}$ & $\mathbf{1 1 , 5}$ & $\mathbf{1 1 , 6}$ & $\mathbf{1 1 , 7}$ & $\mathbf{1 1 , 7}$ \\
\hline 42,5 & $\mathbf{1 1 , 0}$ & $\mathbf{1 1 , 1}$ & $\mathbf{1 1 , 7}$ & $\mathbf{1 2 , 5}$ & $\mathbf{1 3 , 0}$ & $\mathbf{1 3 , 0}$ & $\mathbf{1 2 , 8}$ & $\mathbf{1 2 , 7}$ & $\mathbf{1 2 , 9}$ & $\mathbf{1 3 , 3}$ & $\mathbf{1 3 , 6}$ & $\mathbf{1 4 , 0}$ & $\mathbf{1 4 , 4}$ \\
\hline 40 & $\mathbf{1 3 , 5}$ & $\mathbf{1 3 , 9}$ & $\mathbf{1 4 , 7}$ & $\mathbf{1 5 , 6}$ & $\mathbf{1 5 , 8}$ & $\mathbf{1 5 , 4}$ & $\mathbf{1 4 , 8}$ & $\mathbf{1 4 , 5}$ & $\mathbf{1 4 , 7}$ & $\mathbf{1 5 , 1}$ & $\mathbf{1 5 , 6}$ & $\mathbf{1 6 , 1}$ & $\mathbf{1 6 , 7}$ \\
\hline
\end{tabular}

ния климатических показателей по регионам и сезонам года.

Целью нашего исследования является месячное детальное изучение климатических параметров приземного поля температуры воздуха в Восточной части Европы в весенний период (на примере апреля месяца). В качестве объекта исследования рассматривался сектор территории Восточной Европы, ограниченный широтами 40-60 с.ш. и долготами $30-60^{\circ}$ в.д.

В качестве исходных данных использовались средние месячные значения температуры воздуха в апреле, за период с 1958 по 2015 годы. Информационной базой служили данные реанализа [11, 12, 13] на поверхности 1000 гПа на территории Восточной Европы в узлах регулярной сетки $i, j$ с шагом $2,5^{\circ}$. В каждом узле регулярной сетки $i, j$ по формуле (1), рассчитывались «климатические нормы» средних месячных значений температуры воздуха $\bar{T}_{i, j}$, названные в дальнейшем, для краткости, «нормами».

$$
\bar{T}_{i, \bar{j}}=\frac{1}{N} \sum_{t=1}^{N} T_{i, j, t},
$$

где $T_{i, j, t}$ - средняя месячная температура воздуха в узле $i, j ; i$ - порядковый номер широты; $j$ - порядковый номер долготы; $t$ - порядковый номер года в выборке; $N$ - число используемых лет.

Для выявления особенностей в распределении средних многолетних значений температуры в современных условиях, в сопоставлении их с более ранним периодом, используемая выборка была разделена на два периода. В первый период - включены годы с 1958 по 1979, которые входят в «климатическую норму 1961-1990 годов», используе- мую в настоящее время в качестве репера. В выборку второго периода входили данные с 1980 по 2015 годы, характеризующие термический режим современного периода.

Результаты расчета в узлах регулярной сетки $i$, $j$ точечных «норм» средней месячной температуры воздуха $\bar{T}_{i, j}$ за первый период с 1958 по 1979 годы представлены в таблице 1.

При анализе результатов таблицы 1 обращает на себя внимание наличие неоднородности в пространственном распределении средних многолетних значений температуры $\bar{T}_{i, j}$, обусловленной разной подстилающей поверхностью, широтной неоднородностью, степенью удаленности от крупных водоемов и лесных массивов. Поэтому минимальная температура воздуха отмечается на крайней северной широте $\left(60^{\circ}\right.$ с.ш.). Температура уменьшается с запада на восток, находясь в пределах $2,4-0,6^{\circ} \mathrm{C}$.

При смещении с севера на юг температура воздуха повышается. В средних широтах она находится в диапазоне $7-9^{\circ} \mathrm{C}$, достигая максимальных значений на широте $40^{\circ}$ с.ш. Здесь температура воздуха изменяется от $13,5^{\circ} \mathrm{C}$ на западе до $16,7^{\circ} \mathrm{C}$ - на востоке. Различия норм среднемесячной температуры, между западными и восточными районами, не велики и составляют от $1,5^{\circ} \mathrm{C}$ в северных широтах до $3,0^{\circ} \mathrm{C}$ в южных. Зона наиболее высоких значений средних месячных температур, превышающих более $10^{\circ} \mathrm{C}$ (выше среднеширотных), с юга ограничивается широтой $45^{\circ}$ с.ш. и выделена в таблице 1 жирным шрифтом, является показателем теплообеспеченности сельскохозяйственных культур. Именно таким требованиям, в реперном периоде, соответствуют условия на широтах $40-45^{\circ}$ с.ш. 
Таблица 2

Распределение норм среднемесячной температуры воздуха за 1980-2015 годы в узлах географической сетки с шагом $2,5^{\circ}$, широтная зона 40-60 с.ш., 30-60 в.д., за апрель месяц

\begin{tabular}{|l|c|c|c|c|c|c|c|c|c|c|c|c|c|}
\hline \multicolumn{10}{|c|}{ Восточная долгота, град } \\
\hline $\begin{array}{l}\text { с.ш. } \\
\text { град }\end{array}$ & 30 & 32,5 & 35 & 37,5 & 40 & 42,5 & 45 & 47,5 & 50 & 52,5 & 55 & 57,5 & $60^{\circ}$ \\
\hline 60 & 3,8 & 3,8 & 3,7 & 3,5 & 3,3 & 3,0 & 2,8 & 2,5 & 2,2 & 1,9 & 1,6 & 1,4 & 1,1 \\
\hline 57,5 & 5,4 & 5,2 & 5,1 & 4,9 & 4,7 & 4,5 & 4,2 & 3,9 & 3,6 & 3,4 & 3,2 & $\mathbf{3 , 0}$ & 2,8 \\
\hline 55 & 6,6 & 6,4 & 6,1 & 6,0 & 5,8 & 5,6 & 5,3 & 5,1 & 4,9 & 4,7 & 4,6 & 4,5 & 4,4 \\
\hline 52,5 & 8,2 & 8,0 & 7,8 & 7,7 & 7,5 & 7,4 & 7,2 & 7,0 & 6,8 & 6,6 & 6,5 & 6,4 & 6,3 \\
\hline 50 & 9,6 & 9,5 & 9,4 & 9,4 & 9,4 & 9,4 & 9,3 & 9,2 & 9,1 & 9,0 & 8,9 & 8,7 & 8,5 \\
\hline 47,5 & $\mathbf{1 0 , 2}$ & $\mathbf{1 1 , 1}$ & $\mathbf{1 0 , 2}$ & $\mathbf{1 0 , 3}$ & $\mathbf{1 0 , 5}$ & $\mathbf{1 0 , 6}$ & $\mathbf{1 0 , 8}$ & $\mathbf{1 0 , 9}$ & $\mathbf{1 1 , 1}$ & $\mathbf{1 1 , 3}$ & $\mathbf{1 1 , 3}$ & $\mathbf{1 1 , 3}$ & $\mathbf{1 1 , 2}$ \\
\hline 45 & $\mathbf{1 0 , 7}$ & $\mathbf{1 0 , 6}$ & $\mathbf{1 0 , 7}$ & $\mathbf{1 0 , 9}$ & $\mathbf{1 1 , 1}$ & $\mathbf{1 1 , 3}$ & $\mathbf{1 1 , 6}$ & $\mathbf{1 2 , 0}$ & $\mathbf{1 2 , 5}$ & $\mathbf{1 3 , 1}$ & $\mathbf{1 3 , 6}$ & $\mathbf{1 4 , 0}$ & $\mathbf{1 4 , 2}$ \\
\hline 42,5 & $\mathbf{1 2 , 2}$ & $\mathbf{1 2 , 8}$ & $\mathbf{1 2 , 4}$ & $\mathbf{1 2 , 6}$ & $\mathbf{1 2 , 6}$ & $\mathbf{1 2 , 6}$ & $\mathbf{1 2 , 7}$ & $\mathbf{1 3 , 1}$ & $\mathbf{1 3 , 7}$ & $\mathbf{1 4 , 6}$ & $\mathbf{1 5 , 5}$ & $\mathbf{1 6 , 3}$ & $\mathbf{1 7 , 0}$ \\
\hline 40 & $\mathbf{1 4 , 5}$ & $\mathbf{1 4 , 7}$ & $\mathbf{1 5 , 1}$ & $\mathbf{1 5 , 4}$ & $\mathbf{1 5 , 4}$ & $\mathbf{1 5 , 1}$ & $\mathbf{1 4 , 9}$ & $\mathbf{1 4 , 9}$ & $\mathbf{1 5 , 4}$ & $\mathbf{1 6 , 3}$ & $\mathbf{1 7 , 3}$ & $\mathbf{1 8 , 4}$ & $\mathbf{1 9 , 3}$ \\
\hline
\end{tabular}

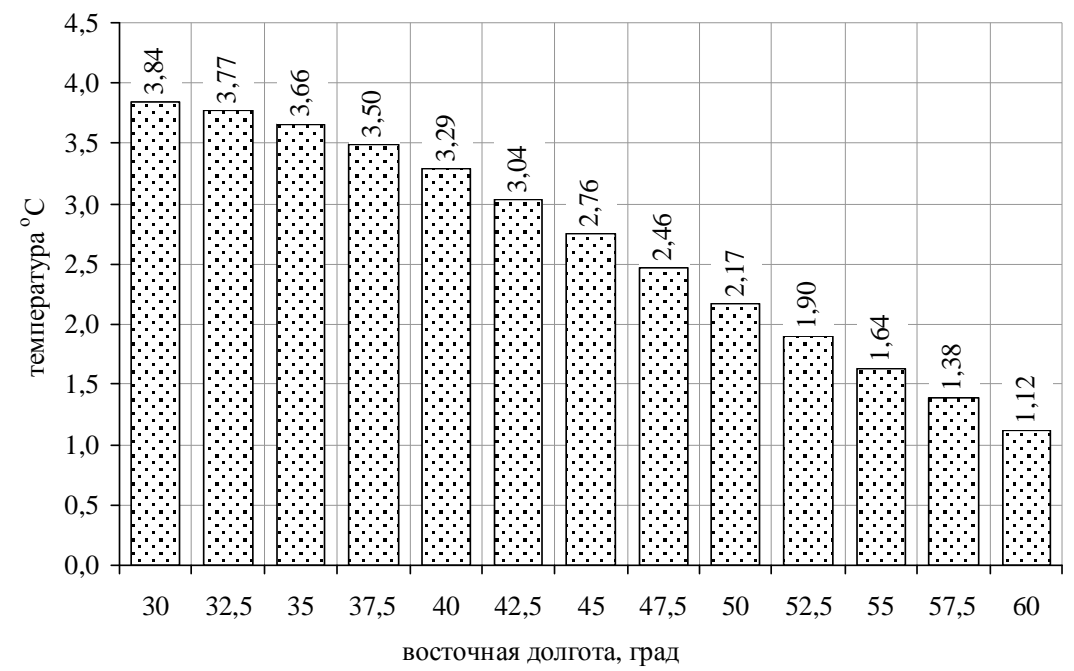

Puc. 1. Изменение средних многолетних температур воздуха по долготам. Апрель (1980-2015)

Для выявления изменений, которые происходят в современных условиях в апреле, в таблице 2 представлено распределение «норм» на территории Восточной Европы, вычисленных за период с 1980 по 2015 годы.

Из анализа таблицы 2 видно, что на всех широтных зонах и рассматриваемых долготах в апреле месяце среднемесячная температура воздуха, как и в предыдущем периоде, положительная, однако уровень ее, по сравнению с предыдущим периодом, значительно выше.

Важно обратить внимание на широту распределения средней месячной температуры, превышающей $10^{\circ} \mathrm{C}$. По сравнению с предыдущим периодом она приподнялась к северу на $2,5^{\circ}$, то есть почти на 300 км и охватывает широты 40-47, $5^{\circ}$ с.ш. Заметно увеличилось количество районов с данной температурой на западе территории. Все это подтверждает выводы Межправительственной группы экспертов по изменению климата (МГЭИК) о наличии положительной тенденции в глобальном повышении температуры воздуха, которая обнаруживаются и при анализе температуры на рассматриваемой территории в весенний период.

Проанализируем характер термического режима на территории Восточной Европы в весенний период более подробно. В современную эпоху сохраняется неоднородность в распределении климатических норм, обусловленных наличием разнообразного рельефа, включая даже слабовсхолмленные участки, способные существенно исказить поле температуры. Прежде всего величины «норм» значительно различаются по широтам. Самые низкие значения среднемесячной температуры отмечаются в апреле в крайних северных широтах $\left(\varphi=60^{\circ}\right.$ с.ш.). Распределение средних мно- 


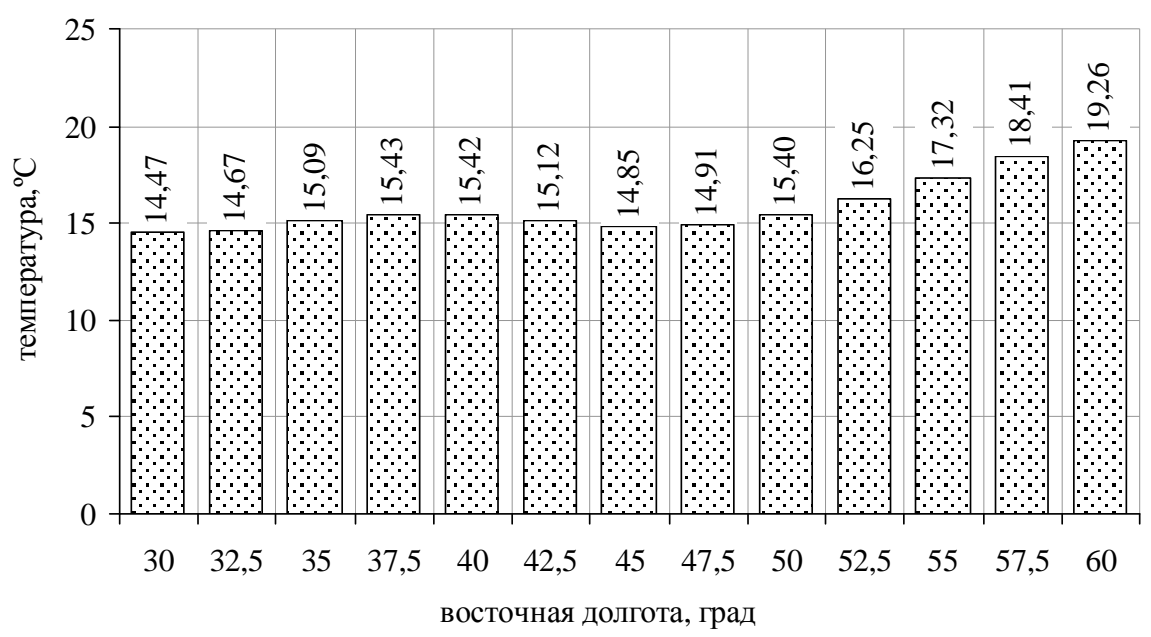

Puc. 2. Изменение средней месячной температуры воздуха по долготам на широте $\varphi=40^{\circ} \mathrm{C}$.

Апрель (1980-2015)

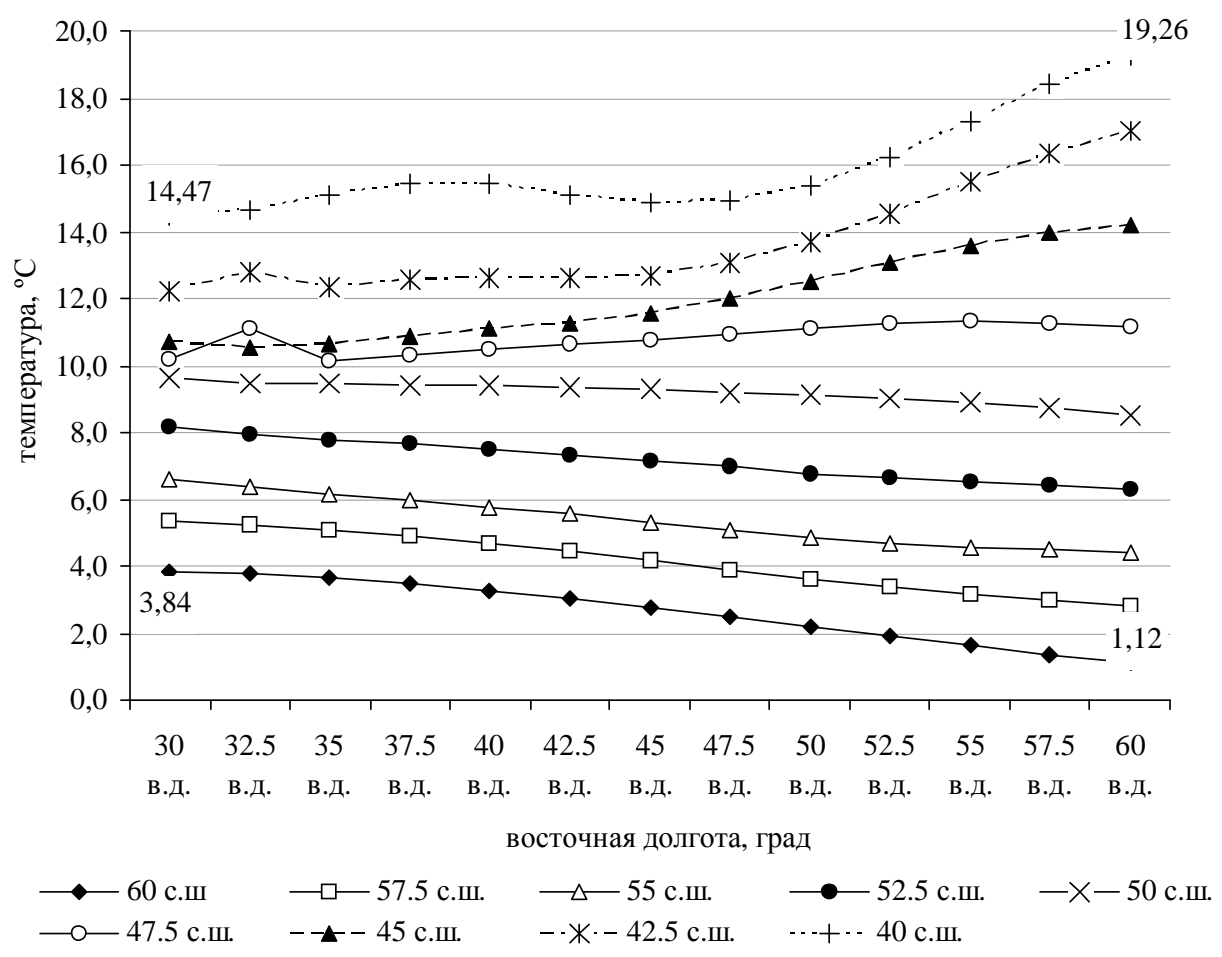

Puc. 3. Распределение по территории средней многолетней температуры воздуха (40-60 с.ш., $30-60^{\circ}$ в.д.). Апрель (1980-2015)

голетних значений температуры воздуха по долготам, на широте $\varphi=60^{\circ}$ с.ш., представлено на рисунке 1.

Из рисунка 1 видно, что максимальная температура на данной широте отмечается на крайней западной долготе $\left(30^{\circ}\right.$ в.д.), где она достигает $3,84^{\circ} \mathrm{C}$. При перемещении с запада на восток температура воздуха понижается, принимая минимальные значения $\left(1,12^{\circ} \mathrm{C}\right)$ на долготе $60^{\circ}$ в.д. Разность между западными и восточными долготами не велика и составляет $2,72^{\circ} \mathrm{C}$ (в реперном периоде она составляет $1,66^{\circ} \mathrm{C}$ ).

Совершенно иной характер распределения по долготам имеет температура воздуха в крайних южных широтах. Для примера, на рисунке 2 представлено изменение температуры воздуха по долготам на широте $\varphi=40^{\circ} \mathrm{C}$.

Как следует из рисунка 2, в южных широтах распределение температуры по долготам, по сравнению с северными широтами, имеет обратный 


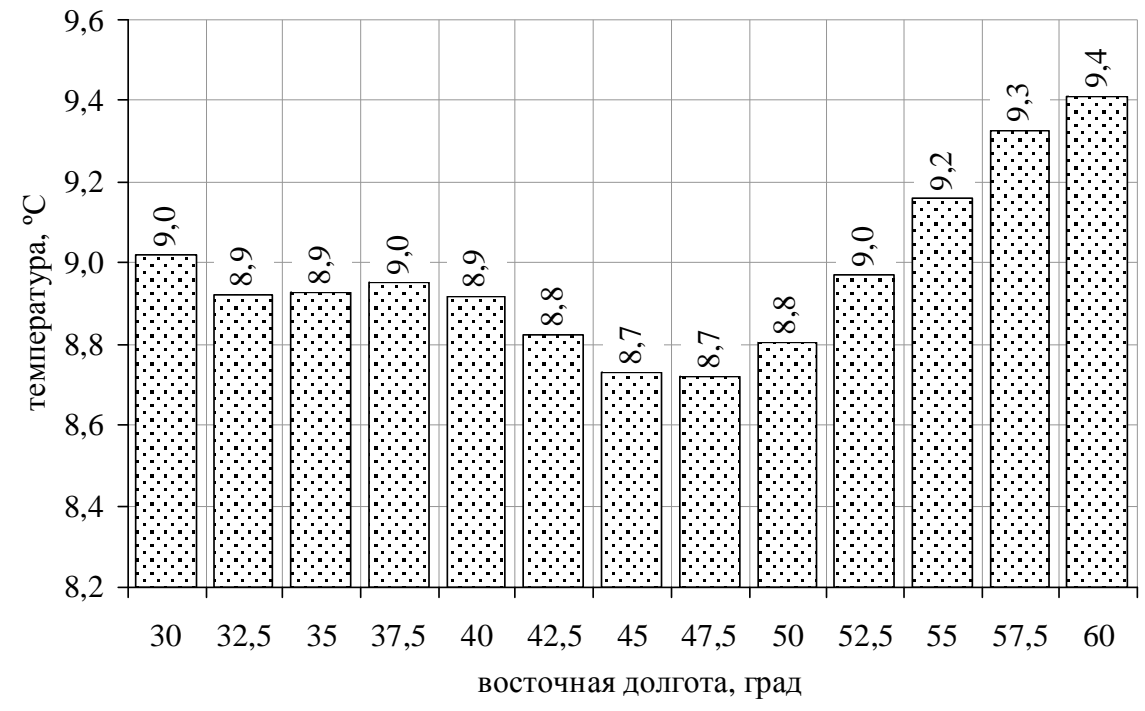

Рuc. 4. Распределение по долготам среднеширотных значений среднемесячной температуры воздуха. Апрель (1980-2015)

характер: минимальные значения температуры отмечаются в западной части рассматриваемой территории, где они не опускаются ниже $14^{\circ} \mathrm{C}$, максимальное - достигается на крайнем востоке Восточной Европы. На таком же уровне находится температура воздуха до $47,5^{\circ}$ в.д., а восточнее начинает монотонно повышаться, достигая максимума $\left(19,26^{\circ} \mathrm{C}\right)$ на $60^{\circ}$ в.д. Таким образом, контраст температур между западными и восточными долготами, по сравнению с северными широтами, увеличился и составляет $4,79^{\circ} \mathrm{C}$. В реперном периоде 1961-1990 годов, он составлял $3^{\circ} \mathrm{C}$.

Важно рассмотреть общий вид климатических норм по исследуемой территории для детального визуального представления о распределении средней месячной температуры на остальных широтах (рис. 3).

По оси абсцисс отложены долготы $j$ с 2,5-ти градусным интервалом. В каждой из них показано распределение среднемесячной температуры воздуха на всех широтах $i$. Так, если в западных районах рассматриваемой территории межширотные различия составляют около $1,5^{\circ} \mathrm{C}$, то на востоке, особенно на южных широтах, они могут достигать $2,2-3,0^{\circ} \mathrm{C}$.

Для выявления особенностей в распределении климатического потенциала, зависящего от средней многолетней температуры воздуха и влияющего на продуктивность сельского хозяйства в весенние месяцы на территории Восточной Европы, по каждой долготе $j$ рассчитаны средние месячные значения температуры, осредненные по всем широтам:

$$
\widetilde{\bar{T}}_{j}=\frac{1}{n} \sum_{i=1}^{n} \bar{T}_{i j},
$$

где $i$ - порядковый номер широты в исследуемом районе, $n$ - общее количество широт $(i=1,2, \ldots, 9)$.

Распределение средних широтных значений температуры по долготам представлено на рисунке 4.

Климатический потенциал термического режима (рис. 4) на рассматриваемой территории в апреле месяце довольно неоднороден. Как оказалось, наибольшим энергетическим запасом тепла обладают восточные районы, находящиеся в промежутке от 55 до $60^{\circ}$ в.д. Здесь средняя многолетняя температура воздуха в полосе от 40 до $60^{\circ}$ с.ш. составляет свыше $9^{\circ} \mathrm{C}$. Максимальное значение $\left(+9,4^{\circ} \mathrm{C}\right)$ приходится на долготу $60^{\circ}$ в.д., а минимально возможный потенциал температуры отмечается на долготах $45-50^{\circ}$ с.ш., где значение осредненной температуры опускается до $+8,5^{\circ} \mathrm{C}$. Приведенные выше результаты исследования могут быть полезными при планировании весенних полевых работ, зависящих от суммарного тепла.

Важным показателем климата является его устойчивость, как показателя величины его изменчивости и насколько, полученным результатам можно доверять? В данной статье для этой цели мы использовали среднее квадратическое отклонение $\sigma$ (сигма), рассчитанное для каждого исследуемого узла $i, j$. Для каждой долготы $j$, представленной с интервалом $2,5^{\circ}$, показана величина среднего квадратического отклонения, отнесенного к каждой из 9-ти исследуемых широт $i$ (рис. 5). 


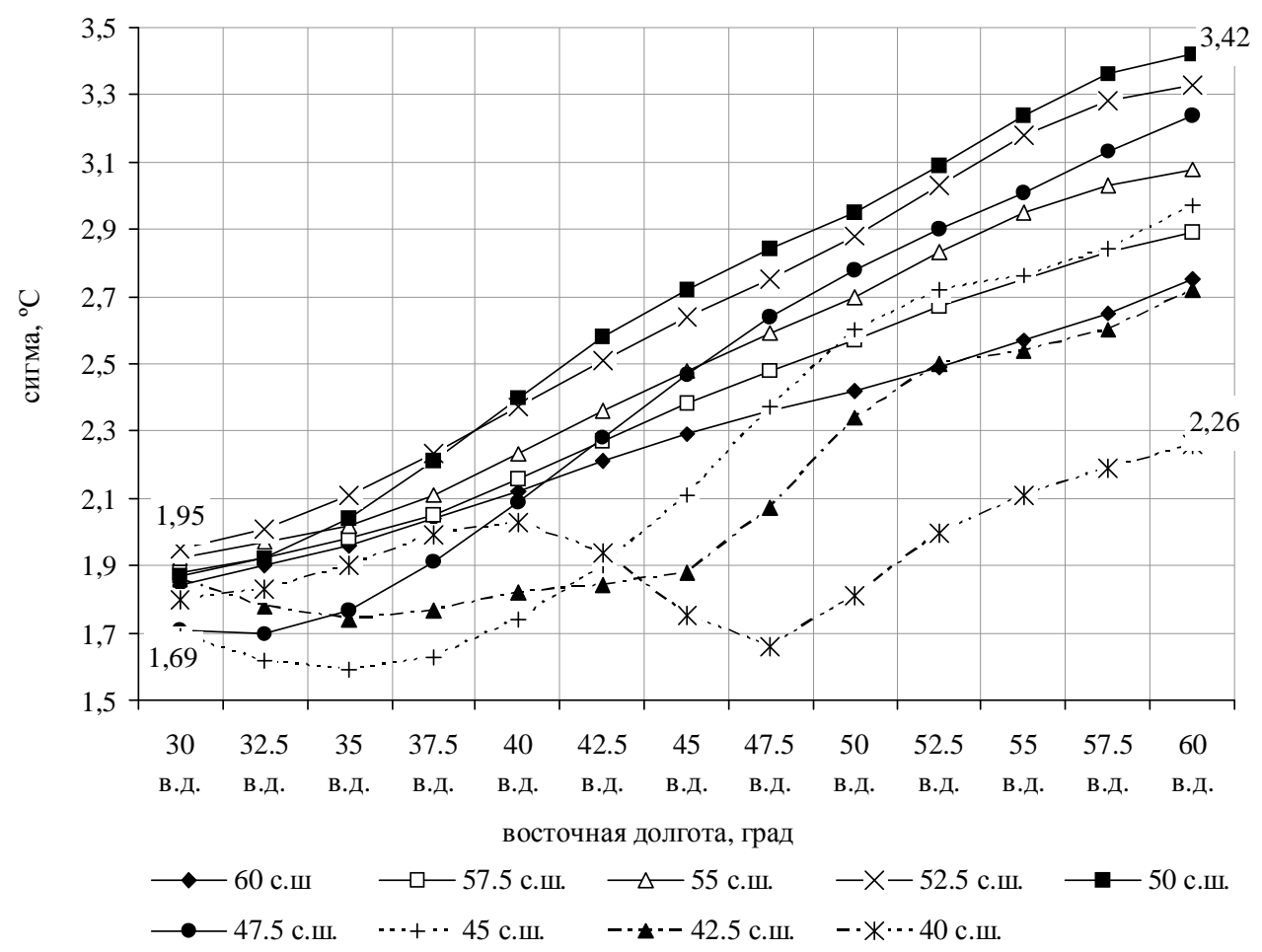

Puc. 5. Изменение средних квадратических отклонений по исследуемой территории (40-60 с.ш. 30-90 в.д.). Апрель

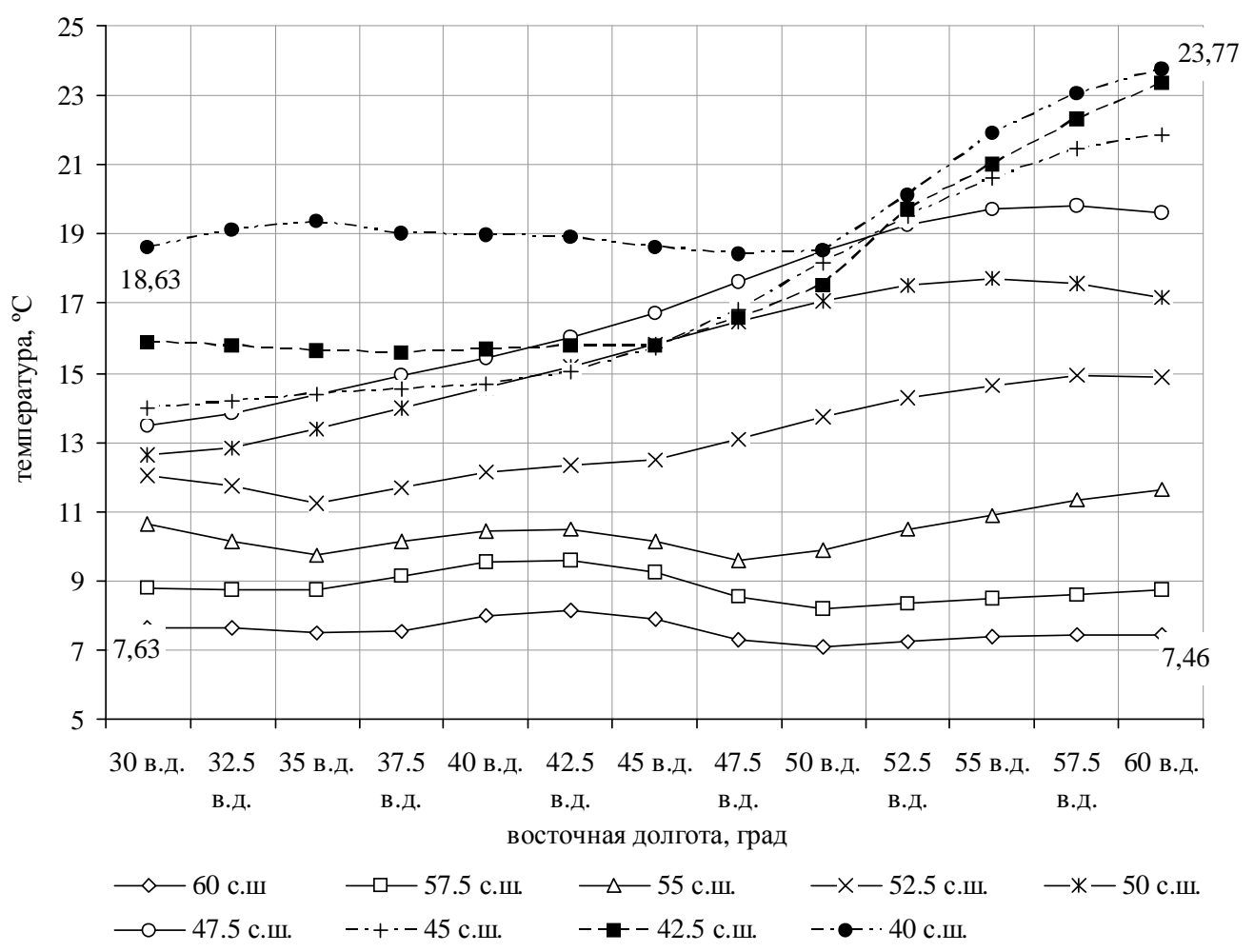

Puc. 6. Распределение значений средних показателей максимальных температур (40-60 с.ш., 30-60 в.д.). Апрель (1980-2015) 


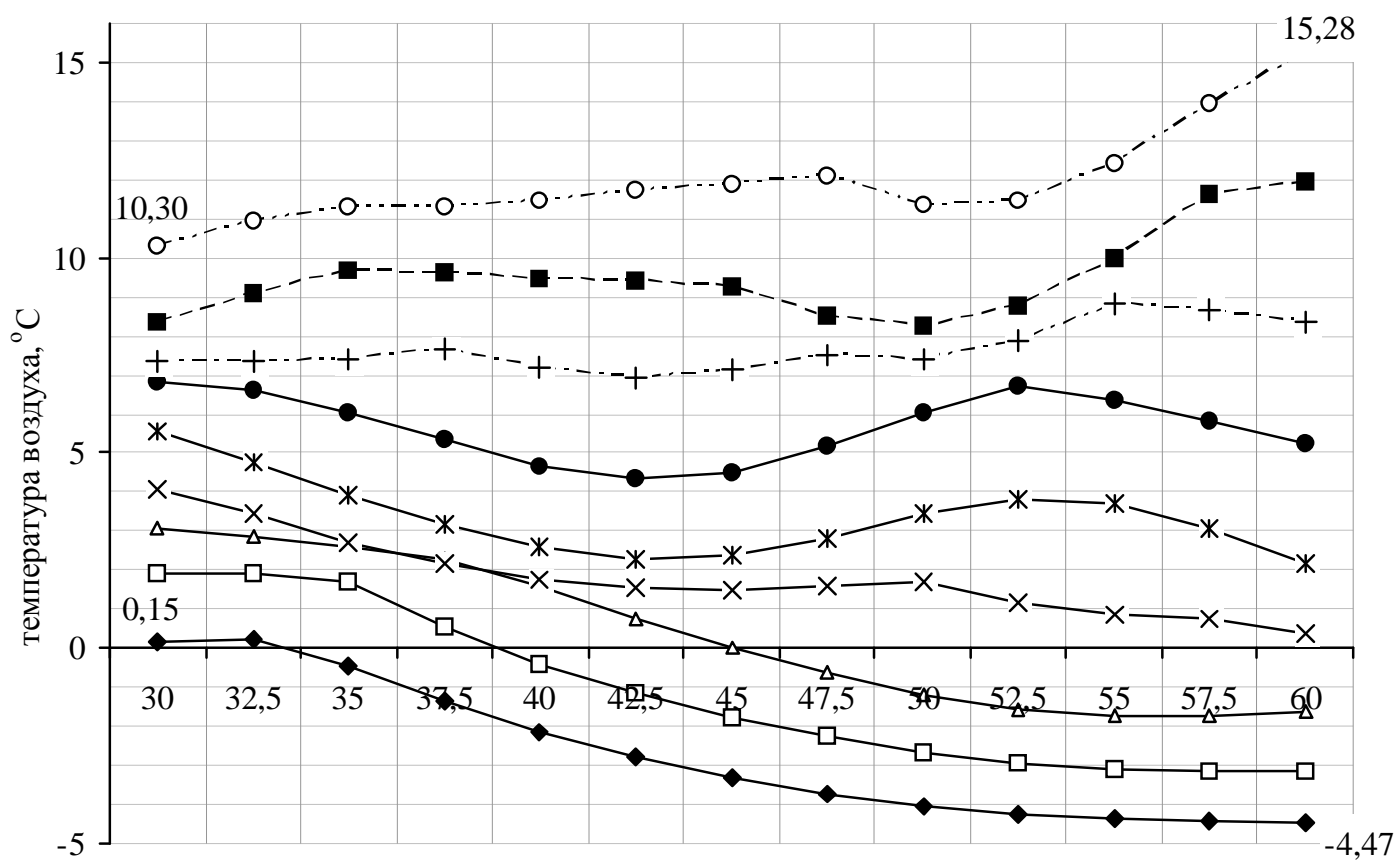

восточная долгота, град

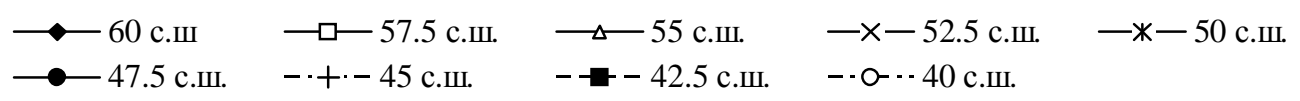

Рис. 7. Изменение по исследуемой территории средних минимальных температур. Апрель (1980-2015)

По результатам комплексного анализа рисунков 3-5 можно сделать вывод, что показатели, как температуры воздуха, так и сигма $\sigma$, неодинаковы. При колебании температуры от, примерно, $2^{\circ} \mathrm{C}$ на западе территории, до $3,5^{\circ} \mathrm{C}$ на востоке. В диапазоне от $30^{\circ}$ в.д. до $37,5^{\circ}$ в.д. среднее квадратическое отклонение мало меняется по широтам. При смещении далее к востоку значения сигмы увеличиваются. Экстремальные значения $\left(3,42^{\circ} \mathrm{C}\right)$ достигаются на широте $50^{\circ}$ в.д. Полученные результаты важно учитывать во всех практических работах при перспективном планировании с использованием современных климатических норм.

Важную роль в практике народного хозяйства, при использовании климатических показателей, играют экстремальные значения средней месячной температуры воздуха. Распределение средних многолетних экстремально высоких значений температуры на исследуемой территории на всех из 9-ти исследуемых широт, для долготы кратной $2,5^{\circ}$, представлено на рисунке 6.

Наиболее высокие значения максимальной температуры воздуха наблюдаются на широте $40^{\circ}$ с.ш. (рис. 6). На большей части территории на долготах от 30 до $50^{\circ}$ в.д. величина максимальных температур на всех широтах находится на уровне $17-18^{\circ} \mathrm{C}$. К востоку уровень температуры повыша- ется и достигает $24^{\circ} \mathrm{C}$. Самая низкая температура отмечается на широте $60^{\circ}$ с.ш., но ее значение по долготам меняется незначительно от $0,15^{\circ} \mathrm{C}$ (на $30^{\circ}$ в.д.) до $-4,47^{\circ} \mathrm{C}$ (на $60^{\circ}$ в.д.). С перемещением к югу максимальная температура увеличивается и на широте $40^{\circ}$ с.ш. достигает значений $10,3^{\circ} \mathrm{C}$ (на $30^{\circ}$ в.д.) и $15,28^{\circ} \mathrm{C}$ (на $60^{\circ}$ в.д.). С запада на восток между южными и северными широтами наблюдается увеличение размаха значений максимальных температур от $10^{\circ} \mathrm{C}$ (на $30^{\circ}$ в.д.) до $20^{\circ} \mathrm{C}$ (на $60^{\circ}$ в.д.).

При планировании посева сельскохозяйственных культур в апреле месяце, важно знать минимальные значения температуры воздуха. Ее распределение по долготам и широтам представлено на рисунке 7.

Как видно из рисунка 7, в апреле, практически на всех долготах, возможно появление отрицательных температур, а их значения по абсолютной величине с запада на восток увеличиваются. Так, если на долготах $30-32,5^{\circ}$ в.д. минимальная температура на широте $60^{\circ} \mathrm{C}$ близка к нулю, то при смещении в восточном направлении, сначала в крайних северных, а затем и в более южных широтах, температура воздуха может опускаться до $-4,5^{\circ} \mathrm{C}$.

Наиболее минимальные температуры отмечаются на широте $40^{\circ}$ в.д. Их значения колеблются 


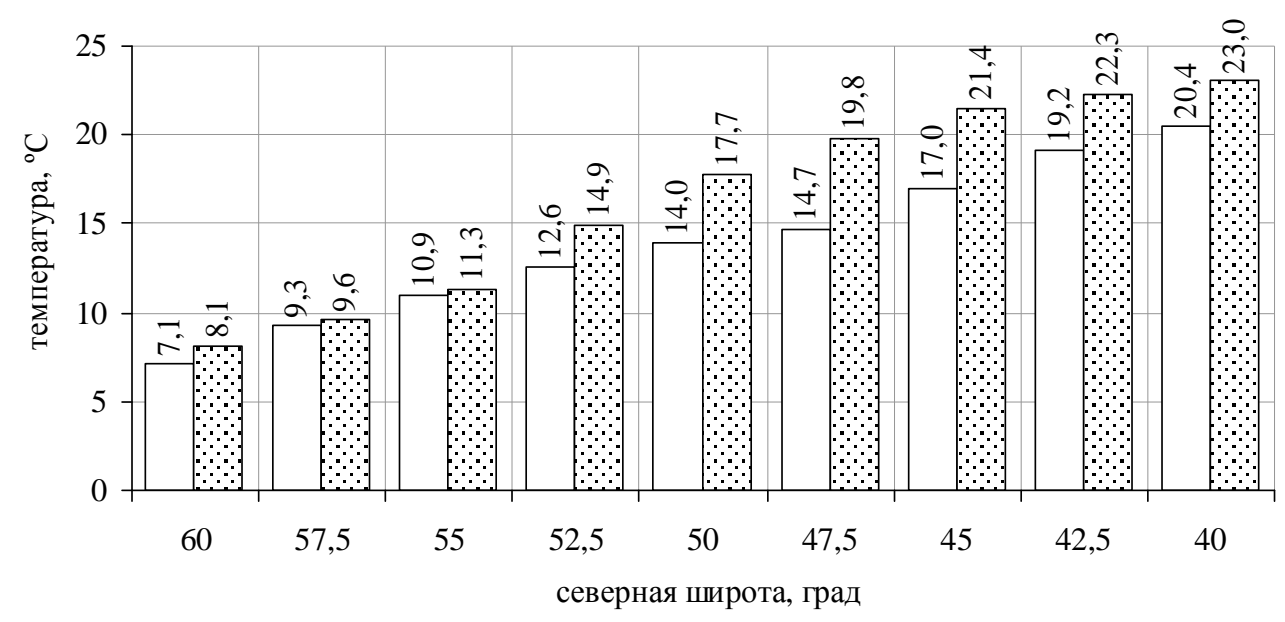

$\square$ 1958-1978 눙 $1979-2015$

Puc. 8. Распределение по широтам максимальных среднеширотных температур воздуха в периодах 1958-1979 и 1980-2018 годы в апреле месяце

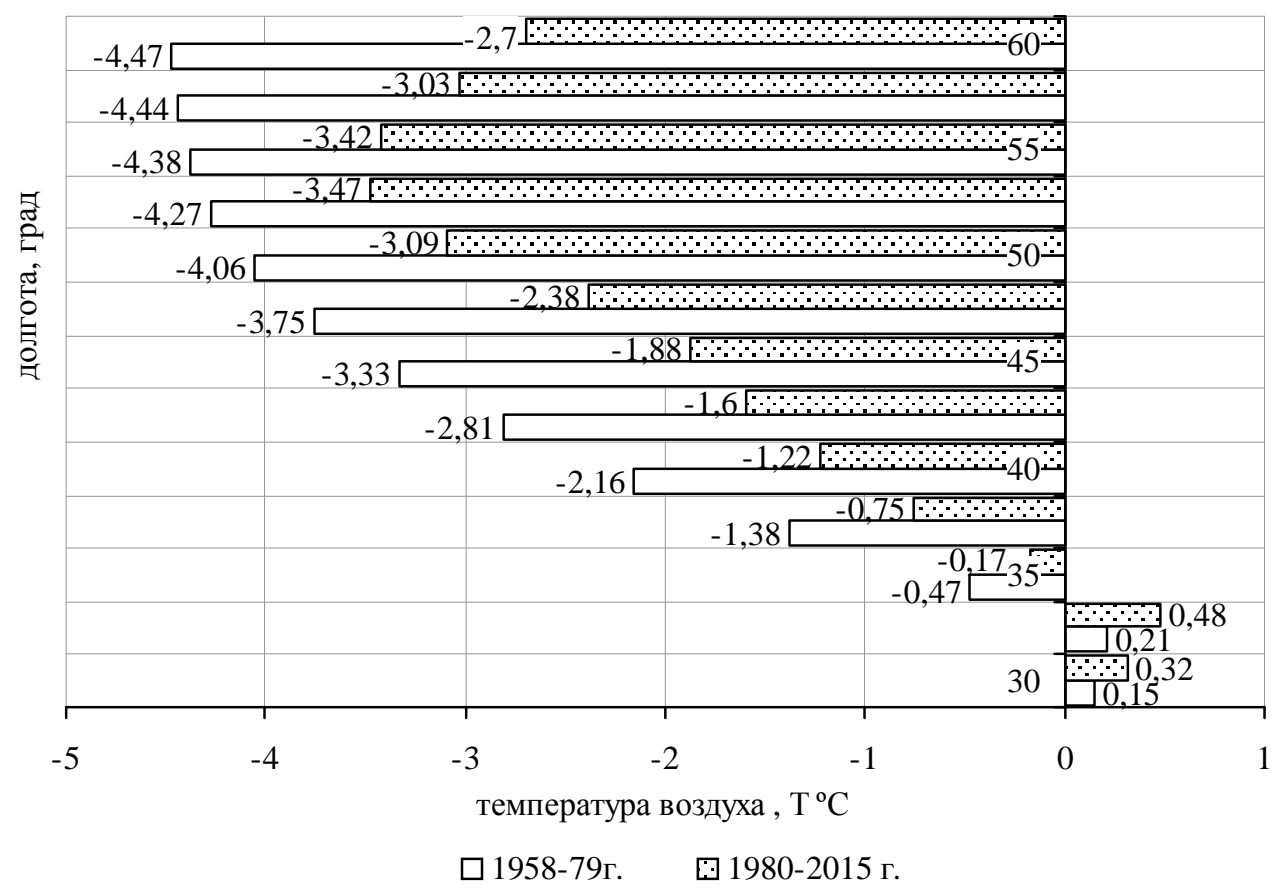

Puc. 9. Изменение по долготам минимальных среднеширотных температур воздуха в периодах 1958-1979 и 1980-2015 годы в апреле месяце

от $10^{\circ} \mathrm{C}$ (на $30^{\circ}$ в.д.) до $15^{\circ} \mathrm{C}$ (на $60^{\circ}$ в.д.). Все представленные результаты анализа характеризуют современный климатический режим, который может быть использован в качестве прогностических рекомендаций при перспективном планировании сельскохозяйственных работ на весенний период.

В заключении рассмотрим, каковы изменения произошли в величинах максимальных и минимальных температур от предшествующего периода (1958-1979) к современному (1980-2015). На рисунке 8 представлены в сопоставлении распре- деления величин максимальных значений в двух исследуемых периодах.

Сравнивая уровни максимальной температуры воздуха в двух рядом стоящих непрерывных периодах, можно сделать однозначный вывод, что максимальная температура воздуха в современных условиях по отношению к предыдущему периоду, заметно повысилась, хотя это повышение на различных долготах происходило не одинаково.

Менее заметное повышение происходило в северных широтах. С $60^{\circ}$ с.ш., до $55^{\circ}$ с.ш., начи- 
ная с широты $52,5^{\circ}$ с.ш., величина повышения максимальной температуры увеличивалась и на широте $40^{\circ}$ с.ш. она достигла $5^{\circ} \mathrm{C}$. Таким образом, положительный тренд температуры наблюдается не только в среднемесячных значениях, но и растет верхний предел максимальной температуры.

На рисунке 9 сопоставлены минимальные температуры воздуха в предшествующий и современный периоды.

Из рисунка 9 отчетливо видно насколько повысилась по абсолютной величине минимальная температура воздуха в современном периоде по сравнению с реперным на всех долготах, что свидетельствует о повышении температуры воздуха. На долготах $30-35^{\circ}$ в.д. температура воздуха и в одном и другом периодах положительная, но в современных условиях она заметно выше, что свидетельствует о положительной тенденции, которую необходимо учитывать в практической деятельности.

Проведенный детальный анализ средних месячных температур воздуха на территории Восточной Европы за апрель месяц в различный временной интервал, позволил выявить средний уровень климатического режима приземной температуры воздуха на рассматриваемой территории, его возможные колебания на различных участках и границы, в которых могут наблюдаться минимальные и максимальные значения. Анализ результатов подтвердил вывод МГЭИК о продолжающемся глобальном потеплении. Уточнена величина этого потепления в широтном и долготном направлениях.

Полученные результаты могут использоваться в качестве показателя теплообеспечения растительного покрова. Они будут полезными при региональном планировании размещения сельскохозяйственных и лесных культур в весенний период. Результаты исследования могут использоваться при разработке численного прогноза погоды и моделировании климата.

\section{СПИСОК ЛИТЕРАТУРЫ}

1. Акимов Л. М. Исследование динамики многолетнего ряда температуры в целях разработки сверхдолгосрочного прогноза / Л. М. Акимов, Т. Н. Задорожная // Вестник Воронежского государственного университета. Сер. География. Геоэкология. - 2014. - № 3. C. 35-39.

2. Акимов Л. М. Многолетние изменения температуры воздуха города Воронежа во второй половине 20-го века / Л. М. Акимов // Вестник Воронежского государственного университета. Сер. География. Геоэкология. - 2009. - № 2. - С. 137-141.
3. Акимов Л. М. Пространственно-временные закономерности распределения климатических характеристик на территории Воронежской области / Л. М. Акимов // Вестник Воронежского государственного университета. Сер. География. Геоэкология. -2013. - № 1. - C. 192-198.

4. Гидротермические тенденции и ответные реакции геосистем на региональные климатические изменения в Воронежской области / В. И. Федотов [и др.]. Воронеж, 2013. - 100 с. - (Деп в ВИНИТИ 18.03.2013, № 77-B2013).

5. Доклад Росгидромета об особенностях климата на территории Российской Федерации за 2013 год. Москва : Росгидромет, 2014. - 246 с.

6. Доклад об особенностях климата на территории Российской Федерации за 2016. - Москва : Росгидромет, 2017. $-70 \mathrm{c}$.

7. Изменение климата. Информационный бюллетень. - Москва : Росгидромет, 2016. - № 58. - 25 с.

8. Оценочный доклад об изменениях климата и их последствиях на территории Российской Федерации. Т. 1. Изменения климата. - Москва : Росгидромет, 2008. $-227 \mathrm{c}$.

9. Платова Т. В. Климатическая характеристика некоторых показателей экстремальности температуры приземного воздуха и атмосферных осадков на территории России. / Т. В. Платова // Использование и охрана природных ресурсов в России : бюллетень. - 2007. № 1. - C. 38-47.

10. Спорышев П. В. Пространственно-временные особенности глобального потепления / П. В. Спорышев, В. М. Катцов // Доклады Академии наук. - 2006. - Т. 410, № 4. - C. 532-537.

11. IPCC (Intergovernmental Panel on Climate Change), 2007. Climate Change 2007: The Physical Science Basis. Contribution of Working Group I to the Fourth Assessment Report of the Intergovernmental Panel on Climate Change. - Cambridge, United Kingdom; New York, USA, 2007. - $996 \mathrm{p}$.

12. IPCC, 2013. Climate Change 2013: The Physical Science Basis. Contribution of Working Group I to the Fifth Assessment Report of the Intergovernmental Panel on Climate Change. - Cambridge, United Kingdom; New York, USA, 2013. - $1535 \mathrm{p}$.

13. NCEP Model Analyses \& Forecasts / National Oceanic and Atmospheric Administration [Электронный pecypc]. - URL: http://products.weather.gov/pdd/ ncepmaf.pdf (дата обращения: 12.04.2016).

\section{REFERENCES}

1. Akimov L. M. Issledovaniye dinamiki mnogoletnego ryada temperatury $\mathrm{v}$ tselyakh razrabotki sverkhdolgosrochnogo prognoza / L. M. Akimov, T. N. Zadorozhnaya // Vestnik Voronezhskogo gosudarstvennogo universiteta. Ser. Geografiya. Geoekologiya. - 2014. - № 3. - S. 35-39.

2. Akimov L. M. Mnogoletniye izmeneniya temperatury vozdukha goroda Voronezha vo vtoroy polovine 
20-go veka / L. M. Akimov // Vestnik Voronezhskogo gosudarstvennogo universiteta. Ser. Geografiya. Geoekologiya. - 2009. - № 2. - S. 137-141.

3. Akimov L. M. Prostranstvenno-vremennyye zakonomernosti raspredeleniya klimaticheskikh kharakteristik na territorii Voronezhskoy oblasti / L. M. Akimov // Vestnik Voronezhskogo gosudarstvennogo universiteta. Ser. Geografiya. Geoekologiya. - 2013. - № 1. - S. 192-198.

4. Gidrotermicheskiye tendentsii i otvetnyye reaktsii geosistem na regional'nyye klimaticheskiye izmeneniya $\mathrm{v}$ Voronezhskoy oblasti / V. I. Fedotov [i dr.]. - Voronezh, 2013. - 100 s. - (Dep v VINITI 18.03.2013, № 77-V2013).

5. Doklad Rosgidrometa ob osobennostyakh klimata na territorii Rossiyskoy Federatsii za 2013 god. - Moskva : Rosgidromet, 2014. - $246 \mathrm{~s}$.

6. Doklad ob osobennostyakh klimata na territorii Rossiyskoy Federatsii za 2016. - Moskva : Rosgidromet, 2017. $-70 \mathrm{~s}$.

7. Izmeneniye klimata. Informatsionnyy byulleten'. Moskva : Rosgidromet, 2016. - № 58. - 25 s.

8. Otsenochnyy doklad ob izmeneniyakh klimata i ikh posledstviyakh na territorii Rossiyskoy Federatsii. T. 1. Izmeneniya klimata. - Moskva : Rosgidromet, 2008. - 227 s.

\section{Акимов Леонид Мусамудинович}

кандидат географических наук, доцент, зав. кафедрой природопользования факультета географии, геоэкологии и туризма Воронежского государственного университета, г. Воронеж, т. (473) 266-56-54, E-mail: ak163@bk.ru, geoecolog@ mail.ru

Задорожная Тамара Николаевна кандидат географических наук, доцент Военного учебно-научного центра Военно-воздушных сил «Военновоздушная академия им. профессора Н.Е. Жуковского и Ю.А. Гагарина» Министерства обороны Российской Федерации, г. Воронеж, E-mail: vaiu@ mail.ru

\section{Закусилов Вадим Павлович}

кандидат географических наук, доцент Военного учебно-научного центра Военно-воздушных сил «Военновоздушная академия им. профессора Н.Е. Жуковского и Ю.А. Гагарина» Министерства обороны Российской Федерации, г. Воронеж, E-mail: vaiu@ mail.ru
9. Platova T. V. Klimaticheskaya kharakteristika nekotorykh pokazateley ekstremal'nosti temperatury prizemnogo vozdukha i atmosfernykh osadkov na territorii Rossii. / T. V. Platova // Ispol'zovaniye i okhrana prirodnykh resursov v Rossii : byulleten'. - 2007. - № 1. - S. 38-47.

10. Sporyshev P. V. Prostranstvenno-vremennyye osobennosti global'nogo potepleniya / P. V. Sporyshev, V. M. Kattsov // Doklady Akademii nauk. -2006. - T. 410, № 4. - S. 532-537.

11. IPCC (Intergovernmental Panel on Climate Change), 2007. Climate Change 2007: The Physical Science Basis. Contribution of Working Group I to the Fourth Assessment Report of the Intergovernmental Panel on Climate Change. - Cambridge, United Kingdom; New York, USA, 2007. - 996 p.

12. IPCC, 2013. Climate Change 2013: The Physical Science Basis. Contribution of Working Group I to the Fifth Assessment Report of the Intergovernmental Panel on Climate Change. - Cambridge, United Kingdom; New York, USA, 2013. - $1535 \mathrm{p}$.

13. NCEP Model Analyses \& Forecasts / National Oceanic and Atmospheric Administration [Elektronnyy resurs]. - URL: http://products. weather.gov/pdd/ncepmaf.pdf (data obrashcheniya : 12.04.2016).

\section{Akimov Leonid Musamudinovitch}

Candidate of Geographical Sciences, Associate Professor, Head of the Department of nature management, Faculty of Geography, Geoecology and Tourism, Voronezh State University, Voronezh, tel. (473) 266-56-54, E-mail: ak163@bk.ru, geoecolog@ mail.ru

Zadorozhnaya Tamara Nikolayevna

Candidate of Geographical Sciences, Associate Professor of the Military Educational and Scientific Centre of the Air Force, «Air Force Academy named after professor N.E. Zhukovsky and Yu.A. Gagarin» of the Ministry of Defense of the Russian Federation, Voronezh, E-mail: vaiu@mil.ru

Zakusilov Vadim Pavlovitch

Candidate of Geographical Sciences, Associate Professor of the Military Educational and Scientific Centre of the Air Force, «Air Force Academy named after professor N.E. Zhukovsky and Yu. A. Gagarin» of the Ministry of Defense of the Russian Federation, Voronezh, E-mail: vaiu@mil.ru 